\title{
Authors' Response to Drs. Ece Salihoglu and Ziya Salihoglu's Letter to the Editor
}

\author{
Sophie E. Morton (i), ${ }^{1}$ Jennifer L. Knopp,${ }^{1}$ J. Geoffrey Chase, ${ }^{1}$ Knut Möller, ${ }^{2}$ Paul Docherty, ${ }^{1}$ \\ Geoffrey M. Shaw, ${ }^{3}$ and Merryn Tawhai ${ }^{4}$ \\ ${ }^{1}$ Department of Mechanical Engineering, University of Canterbury, Christchurch, New Zealand; ${ }^{2}$ Institute of Technical \\ Medicine, Furtwangen University, Villingen-Schwenningen, Germany; ${ }^{3}$ Department of Intensive Care, Christchurch Hospital, \\ Christchurch, New Zealand; and ${ }^{4}$ Auckland Bioengineering Institute, The University of Auckland, Auckland, New Zealand
}

(Received 25 July 2019; accepted 6 August 2019; published online 13 August 2019)

Associate Editor Stefan M. Duma oversaw the review of this article.

To the Editor,

We would like to thank Drs. Ece Salihoglu and Ziya Salihoglu for their interest in our article. ${ }^{2}$

While not directly addressed in the paper, the CURE clinical study data used in this paper considers patient gas concentration alongside both ventilator pressure and volume. The four CURE pilot trial patients had $\mathrm{FiO}_{2}$ set to 40, 40, 55 and 65 with $\mathrm{PaO}_{2}$ measurements of 71, 84, 60 and $101 \mathrm{mmHg}$, respectively. The McREM trial data used for validation did not provide specific oxygenation results. ${ }^{3}$ However, each patient's initial $\mathrm{P} / \mathrm{F}$ ratio is provided in Table 1 of the paper, and indicates $\mathrm{FiO}_{2}$ varied in typical ranges. ${ }^{3}$

The model presented in our paper was designed for use in an upcoming clinical trial that aims to optimise mechanical ventilation care. ${ }^{1,4}$ The trial uses two steps to optimise oxygenation. Step 1 optimises alveolar recruitment by titrating PEEP to the point of minimum elastance. The model thus safely maximises oxygenation via mechanics without adjusting $\mathrm{FiO}_{2}$. Step 2 uses this foundation to titrate $\mathrm{FiO}_{2}$ to achieve patient $\mathrm{SpO}_{2}$ levels within $92-95 \%$. This process minimises the risk

Address correspondence to Sophie E. Morton, Department of Mechanical Engineering, University of Canterbury, Christchurch, New Zealand. Electronic mails: sophie.morton@pg.canterbury.ac.nz, jennifer.knopp@canterbury.ac.nz, geoff.chase@canterbury.ac.nz, moe@hs-furtwangen.de, paul.docherty@canterbury.ac.nz, geoff.shaw@cdhb.health.nz,m.tawhai@auckland.ac.nz

This comment refers to the article available at https://doi.org/10. 1007/s10439-019-02253-w. of excessively high oxygen levels, so the broad range of patients with respiratory failure can be optimally treated dependent on their specific condition and response to ventilation.

Thank you again for your time and interest.

\section{ACKNOWLEDGMENTS}

Funding was provided by NZ Tertiary Education Commission (TEC) fund MedTech CoRE (Grant No. E6391), NZ National Science Challenge 7, Science for Technology and Innovation (Grant No. E6525), Engineering Technology-based Innovation in Medicine (eTIME) consortium grant (eTIME 318943) and EU FP7 International Research Staff Exchange Scheme (IRSES) grant (\#PIRSES-GA-2012-318943).

\section{REFERENCES}

\footnotetext{
${ }^{1}$ Morton, S., Y. Chiew, C. Pretty, E. Moltchanova, C. Scarrott, D. Redmond, G. Shaw, and J. Chase. Effective sample size estimation for a mechanical ventilation trial through Monte-Carlo simulation: length of mechanical ventilation and ventilator free days. Math. Biosci. 284:2131, 2017.

${ }^{2}$ Morton, S. E., J. L. Knopp, J. G. Chase, K. Möller, P. Docherty, G. M. Shaw, and M. Tawhai. Predictive virtual patient modelling of mechanical ventilation: impact of recruitment function. Ann. Biomed. Eng. 47:1626-1641, 2019.

${ }^{3}$ Stahl, C. A., K. Möller, S. Schumann, R. Kuhlen, M. Sydow, C. Putensen, and J. Guttmann. Dynamic versus static respiratory mechanics in acute lung injury and acute respi-
} 
ratory distress syndrome. Crit. Care Med. 34:2090-2098, 2006.

${ }^{4}$ Szlavecz, A., Y. S. Chiew, D. Redmond, A. Beatson, D. Glassenbury, S. Corbett, V. Major, C. Pretty, G. M. Shaw, and B. Benyo. The Clinical Utilisation of Respiratory Elastance Software (CURE Soft): a bedside software for real-time respiratory mechanics monitoring and mechanical ventilation management. Biomed. Eng. Online 13:140, 2014.

Publisher's Note Springer Nature remains neutral with regard to jurisdictional claims in published maps and institutional affiliations. 